\title{
Student errors: how teachers diagnose and respond to them
}

\author{
Jürgen Seifried ${ }^{\mathrm{a}}$, Eveline Wuttke ${ }^{\mathrm{b}},{ }^{*}$ \\ ${ }^{a}$ University of Konstanz, ${ }^{b}$ Goethe University of Frankfurt
}

\begin{abstract}
Current pedagogical discourse has established that teacher competence is a conditio sine qua non for high level performance in the classroom. Nevertheless questions of conceptualising and measuring teacher competence have yet to be answered. In our study we analyse a facet of teacher competence essential to successful learning processes; namely, teacher competence when diagnosing and responding to student errors in a constructive manner. Two pilot studies investigate how students perceive «error culture» in their classrooms, and how teachers deal with learner errors during lessons.
\end{abstract}

Keywords: professional competence, error learning, error culture

\section{Professional error competence in teachers: creating a positive error culture and responding constructively to student errors}

Generally it is assumed that a teacher's competence determines his or her classroom performance and this in turn effects how students learn. This cause-and-effect chain is plausible but has yet to be substantiated empirically (e.g. Cochran-Smith, 2001; Baumert \& Kunter, 2006; Desimone, 2009; Galluzzo \& Graig, 1990; Kunter et al., 2007). Therefore research leading to a concretisation of pertinent qualifications, especially during teacher education, is important. This is also true of teacher error competence. In the following we focus on three particular facets that are central to our research and which we term the professional error competence (PEC) of teachers:

- an understanding and knowledge of common learner errors and difficulties in learning;

- an understanding and knowledge of strategies for dealing with those errors and difficulties;

- beliefs regarding the benefit of analysing student errors during lessons. ${ }^{1}$

* Corresponding Author: Jürgen Seifried, University of Konstanz, Department of Economics, Business and Economics Education, Box 123, D-78457 Konstanz, Telephone: +49-7531-88-2192, e-mail: juergen.seifried@uni-konstanz.de. The authors would like to thank the reviewers for their constructive comments that helped to improve the manuscript.

1 According to Schoenfeld the «world view» of a teacher relates to their perception of the role of teaching. Great variation exists within the discussion of these convictions or basic orientations and they are 
We assume that teachers can develop these competencies in the course of their training and professional life. Therefore, corresponding development processes must be depicted using longitudinal study designs (see section 3 ).

In teaching-learning-research the effect of feedback following errors is drawing increasing consideration. Reflections on whether and how one can learn from errors, what errors can be learnt from and how teachers deal with students' errors are all finding growing consideration in teaching-learning-research. The idea that errors can have a potential for learning was rarely supported at first (e.g. Weimer, 1925). However, in recent years many doubts have been raised as to whether the negative assessment and sanction of errors in pedagogical contexts is the most effective approach (Yerushalmi \& Polingher, 2006; Fischer et al., 2006). Of course it is necessary to differentiate between learning situations and work situations. While it is easy to agree that in learning processes mistakes might help knowledge acquisition, in working life, especially in high-risk-domains such as piloting an airplane or the operation of chemical or nuclear plants, errors have to be avoided (Glendon, Clarke \& McKenna, 2006). As work is usually too complex to totally eliminate the potential for errors, dealing with mistakes at the workplace is an important strategy for workplace learning (Harteis, Bauer \& Gruber, 2008). Moreover, some empirical evidence shows a positive relationship between organisational error management culture (e.g. norms and common practices in organisations such as communication regarding errors, their detection, analysis, and rapid correction) and firm performance (van Dyck et al., 2005; Harteis, Bauer \& Gruber, 2008). So, constructive error management in companies requires responsive strategies (Nordstrom, Wendland \& Williams, 1998).

In learning processes, however, mistakes can foster understanding and knowledge building. But the actual process of learning from errors, if it really happens, is still largely a mystery. ${ }^{2}$ As a first step, a systematic conceptualisation of possible error types is necessary for every domain. Some can be found, e.g. in papers by Oser, Hascher \& Spychiger (1999), Oser \& Spychiger (2005), Müller (2003), Große \& Renkl (2007), Gschwendtner, Knöll \& Nickolaus (2007), Gartmeier et al. (2008) and Minnameier (2008), which all attempt systematic and domain-specific foundations and applications. Furthermore, we have theoretical and empirical evidence proving that the teachers' reaction to student errors is crucial to the learning process (to avoid making students feel foolish, to provide a positive atmosphere for errors and to give constructive response to errors, Spychiger et al., 1998). But although some suggestions can be found in Yerushalmi \& Polingher (2006) as well as in Mindnich, Wuttke \& Seifried (2008), concrete guidelines outlining how errors should be dealt with

hardly ever systematically compared and sorted. Therefore, in alignment with Schoenfeld (1985, 2002), we use the expression «world view» as an umbrella term for interrelated working models (subjective theories, conceptions of learning and teaching, implicit theories, beliefs etc., see also Bromme, 2005; Seifried, 2009).

2 Even examinations at a physiological level do not paint a homogeneous picture. On one side, results point to the fact that errors have a positive effect on subsequent learning processes (Wills et al., 2007), on the other hand some people, because of an impaired processing of Dopamin, hardly seem to learn from the negative consequences of their actions (Klein et al., 2007). 
have yet to be developed. Accordingly, it is still rather uncertain exactly what competences teachers should have in order to deal with errors constructively.

A possible basis for the modelling of error-learning-processes can be found in the concept of negative knowledge or negative expertise. This idea - we know what we don't know and what we don't know we don't know - was discussed by Alfred Schütz in «Der sinnhafte Aufbau der sozialen Welt» (1932, English translation: «The Phenomenology of the Social World», 1967). More recently Minsky (1994) popularised the concept (see also Oser \& Spychiger, 2005, or Gartmeier et al., 2008). Negative knowledge incorporates both procedural (knowledge, how something does not work, Minsky, 1994) and declarative knowledge (knowledge, how something is not and what one does not know, Parviainen \& Eriksson, 2006). The basic idea is that people recognize their «deficits» and therefore initiate learning processes. Consequently, learning processes can be supported through negative experiences, in that a person will know why something does not work, and in the ideal case, also realise exactly what they do not know or are not capable of. These realisations, especially the latter, would open various opportunities to learn new things (Parviainen \& Eriksson, 2006). It is also assumed that negative knowledge has a heuristic value in the sense that it gives clues as to the corresponding positive knowledge and so enables the use of regulative and adaptive strategies (Eraut, 1994). Thus, the possibility of excluding negatively coded alternatives leads to an increase in certainty (Gartmeier et al., 2008).

Whether the potential connected with the acquisition of negative knowledge can actually develop and result in knowledge acquisition depends on whether deeper reasons for errors are analysed and reflected on and if constructive feedback is given on how to improve in the future. Reflections are considered to be a process of reconsideration and reassessment of experiences and, therefore, should contribute to the development of competence (see results in van Woerkom, 2003, or Ellström, 2006). Teachers should be able to support such processes; but both the extent to which this is possible, and whether the necessary time and space is granted during lessons depends, above all, on the teachers' opinion of errors (flaw versus learning opportunity) and on their competence in dealing with errors. Unfortunately students still frequently report that they perceive a negative error culture, state that they often experience errors as flaws and that learning from errors is not supported systematically by their teachers (Spychiger et al., 1998). If this is the case, future responses to errors might be to either avoid them or cover them up rather than reflecting on and learning from errors. Similar findings from organizational research show that in a negatively oriented climate with competitive goals teams try to cover up mistakes but are willing to learn from mistakes in a positive climate with cooperative goals (Tjosvold et al., 2004). With these factors in mind, we suggest that in order to use students' errors constructively, teachers need to be competent in three ways (three facets of professional error competence, see Mindnich, Wuttke \& Seifried, 2008): 
(1) Knowledge of possible error types: At first, teachers have to actually recognise the specific logical flaws and false assumptions made by students. To be able to do this, teachers need domain-specific knowledge about possible learner errors.

(2) Available strategies of action/teachers reaction: After having recognised the error, teachers must treat it «adequately». For this they have to know about various alternatives of action (e.g. about giving adequate feedback or when it is better to ignore errors).

(3) A constructive view on errors and their use in classroom processes: Roughly speaking, a so-called error-prevention-didactic (errors are to be prevented so that false trains of thought do not become habitual) can be set against a constructive management of errors. In the sense of the latter teachers are prepared to become involved in students errors even if there are time constraints.

\section{Empirical results from two pilot studies}

In two pilot studies we investigated the questions, (1) how students perceive the «error culture» in their classrooms, and (2) how teachers deal with learner errors occurring during lessons. Incentives for pilot study 1 were episodic evidence from Swiss studies showing that the error culture in some schools sometimes is rather negative (Oser \& Spychiger, 2005). We argue that a positive error culture is especially crucial for vocational schools. In companies or at the workplaces - as mentioned above mistakes have to be reduced in order to avoid financial losses, damages or injuries. Vocational schools, however, can establish learning situation close to situations in companies and use mistakes as a means to learn from them and to do better in future. Therefore a positive error culture is essential.

\subsection{Pilot Study 1: «Error culture»}

\section{Method and Sample}

For this study, a questionnaire (Spychiger et al., 1998, Spychiger, Kuster, \& Oser, 2006 , see appendix 1$)^{3}$ was used to investigate classroom error culture. It was distributed in 54 classes in (mainly Bavarian) vocational schools. 1,136 students participated in the study (see table 1). As shown in table 1 there were three types of vocational schools:

- Commercial colleges are full-time vocational schools that provide a degree in secondary education («Mittlere Reife») that allows students to continue their studies in vocational high schools or to start vocational education in the dual system.

3 We translated the questionnaire that can be found in the appendix. In our study we used the original German version. There is no evaluation of the English version yet. 
- Specialized secondary schools provide a degree after grade 12 («Fachhochschulreife») that allows students to study at universities of applied sciences.

- Dual vocational schools are part-time schools and rather typical in the German vocational school system: students work in their respective companies for three or four days and attend vocational school for one or two days.

Table 1: Student sample $(\mathrm{n}=1,136)$

\begin{tabular}{ll}
\hline Criteria & Development in the questioning samples \\
\hline Gender: & $698 \mathrm{f}, 387 \mathrm{~m}, 51$ no statement \\
Age (average, range) in years: & $17,9(13$ to 36$)$ \\
Classes: & $54(51 \times$ Bavaria, $2 \times$ Hesse, $1 \times$ Thuringia $)$ \\
Type of school: & \\
- Commercial colleges & 15 classes, $\mathrm{n}=361$ \\
- Specialized secondary schools & 21 classes, $\mathrm{n}=400$ \\
- Dual vocational schools & 18 classes, $\mathrm{n}=375$ \\
\hline
\end{tabular}

The construct of error culture refers to that defined by the Swiss research group led by Fritz Oser. The basic idea is that teachers should always bear in mind that errors are crucial for learning processes in both the acquisition of knowledge and the development of routines (Oser \& Spychiger, 2005). The analysis of errors, which according to the theory of negative knowledge are considered to be a warning system for the acquisition and application of knowledge, requires a pedagogical style that can be identified as a learning-oriented attitude towards errors. So, a constructive error culture describes a learning environment in which, on one hand, the fear of committing an error (emotional component) is reduced, and where, on the other hand, learning processes are encouraged if an error does occur, thereby supporting learning from errors (cognitive component). The error culture is operationalised by means of four subscales with a total of 31 items (all are answered on 4-point scales ranging from $1=$ not true at all to $4=$ completely true; the internal consistencies of the subscales were moderate to high: $.70 \leq$ Cronbach's $\alpha \leq .83$ ). Error friendliness and error anxiety, thereby, describe the emotional, missing transparency of norms and learning orientation the cognitive component of error culture and hence include both a positive and a negative point of view (positive: learning orientation and error friendliness, negative: missing transparency of norms and error anxiety). Table 2 shows the subscales with example items, reliability coefficients, and descriptive statistics. 
Table 2: Questionnaire-subscales with sample items, reliability coefficients (Cronbach's $\alpha$ ), and descriptive statistics

\begin{tabular}{|c|c|c|c|c|c|c|}
\hline Subscales (number of items) & Sample item & Min & Max & $\alpha$ & $M$ & SD \\
\hline Error friendliness (10) & $\begin{array}{l}\text { With our teacher making } \\
\text { mistakes is never bad. }\end{array}$ & 1.00 & 4.00 & .83 & 2.91 & .53 \\
\hline Learning orientation (8) & $\begin{array}{l}\text { Mistakes in class help me to } \\
\text { do it better next time. }\end{array}$ & 1.00 & 4.00 & .73 & 2.72 & .48 \\
\hline $\begin{array}{l}\text { Missing transparency of } \\
\text { norms (8) }\end{array}$ & $\begin{array}{l}\text { When I make a mistake, I } \\
\text { often do not understand } \\
\text { why. }\end{array}$ & 1.00 & 4.00 & .76 & 2.10 & .52 \\
\hline Error anxiety (5) & $\begin{array}{l}\text { I get scared when I make a } \\
\text { mistake in class. }\end{array}$ & 1.00 & 4.00 & .70 & 1.87 & .56 \\
\hline
\end{tabular}

Note: $\mathrm{N}=1,136 ; 4$-point scale: $1=$ not true at all, $2=$ rather not true, $3=$ partly true, $4=$ completely true

The aim of this study was to establish how students assess different facets of the error culture. Whereas the statements on learning orientation and transparency of norms focus on the teachers' competence in dealing with errors constructively, the subscales of error friendliness and error anxiety refer to the emotional experience of the students during the lessons. Here, we assume that students may generally make errors during lessons and therefore expect positive specifications of these subscales.

\section{Empirical Findings}

The results allude to a relatively positive assessment of the error culture. Both «positive» subscales (error friendliness and learning orientation) reach values close to 3 which translates as «partly true», whereas learners reported little fear of making errors or complaints about a missing transparency of norms. Here the ratings are closer to 2 , meaning «rather not true». So, all in all, the results show that the students reported a quite positive error climate (see figure 1). 


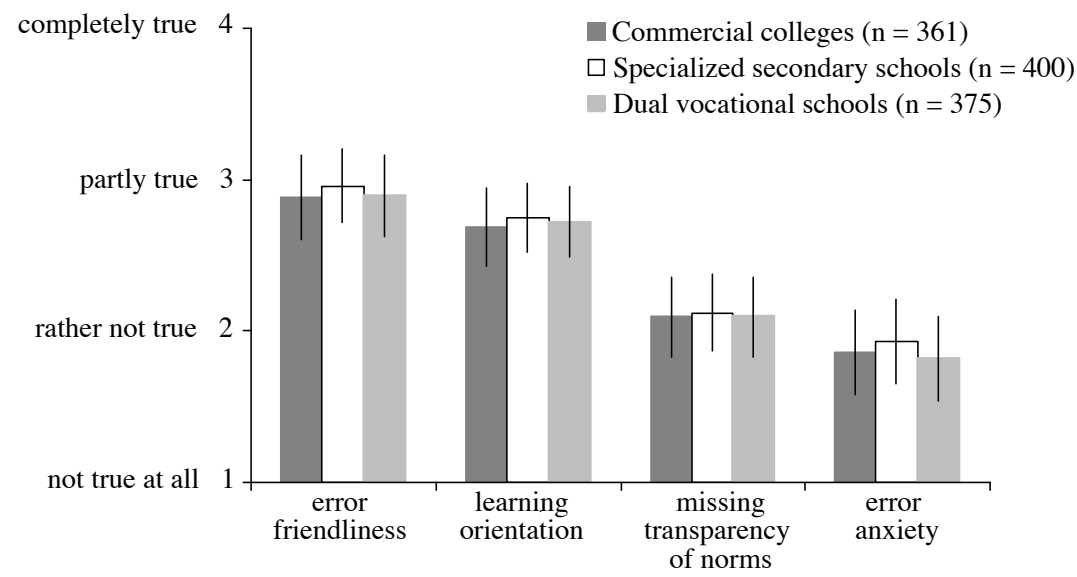

Figure 1: Learners' view of the error culture in classrooms

Additionally, we conducted correlation analyses to determine the relationship between the four subscales. Conforming to expectations, there is a positive correlation between error friendliness and learning orientation. Accordingly, a positive correlation between a missing transparency of norms and error anxiety exists. Furthermore, error friendliness is negative interrelated with both «negative» subscales, and learning orientation is negative linked with missing transparency of norms (see table 3 ).

Table 3: Results of the correlation analysis (Pearson's correlation coefficient)

\begin{tabular}{llll}
\hline Subscale & $(2)$ & $(3)$ & $(4)$ \\
\hline (1) Error friendliness & $0.36^{* *}$ & $-0.59^{* * *}$ & $-0.20^{* *}$ \\
(2) Learning orientation & - & $-0.23^{* *}$ & $0.09^{* *}$ \\
(3) Missing transparency of norms & & - & $0.38^{* *}$ \\
(4) Error anxiety & & & - \\
\hline
\end{tabular}

Note: $\mathrm{N}=1,136 ;{ }^{*}$ : significant at the $1 \%$-level, $*$ : significant at the $5 \%$-level (two-tailed tested)

We also calculated differences between the three types of students investigated (school type) and gender. For the criteria sex we found the following results: There were two significant differences with (very) small effect sizes for the subscales error friendliness $\left(\mathrm{M}_{\text {male }}=2.85, \mathrm{M}_{\text {female }}=2.94, \mathrm{t}=2.831, \mathrm{p}<0.01, \mathrm{~d}=0.18\right)$ and learning orientation $\left(\mathrm{M}_{\text {male }}=2.64, \mathrm{M}_{\text {female }}=2.77, \mathrm{t}=4.167, \mathrm{p}<0.01, \mathrm{~d}=0.26\right)$. For the criteria school-type we found only one significant effect for the subscale error anxiety with once again a very small effect size $\left(\mathrm{M}_{\text {Com. Colleges }}=1.86, \mathrm{M}_{\text {Spec. Sec. Schools }}=1.93, \mathrm{M}_{\text {Dual Voc. }}\right.$ Schools $\left.=1.82, \mathrm{~F}=4.209, \mathrm{p}<0.05, \eta^{2}=0.07\right)$. Finally, we ran correlation analyses with 
regard to the age of the students. There is little correlation between the age and the subscales error friendliness $\left(\mathrm{r}=0.09^{* *}\right)$, learning orientation $\left(\mathrm{r}=0.12^{* *}\right)$ and missing transparency of norms $\left(\mathrm{r}=-0.08^{*}\right)$. All in all, we found no significant evidence that the students' biographical characteristics influenced their perception of error culture in the classroom.

As mentioned above, it is the subscales learning orientation and missing transparency of norms that should, in particular, determine our conclusions about the competent dealing with errors in class. However, the restrictions of individual self reports need to be considered. For example, it would be plausible that learners pay attention, first of all, to emotional aspects such as anxiety or shame, and assess the error culture more positively when the teacher allows errors and does not expose learners' faults. The extent to which learners can actually judge a teacher's success has to remain undefined at this point as students' self reports cannot completely and adequately reflect the constructive handling of error situations. An additional questionnaire of teacher's responses also gave inconclusive results. Because of this, we resorted to observations of lessons in the second pilot study (see section 2.2).

In conclusion we need to evaluate our findings in comparison to similar studies within the field. Two reference studies exist in the fields of general education and mathematics; namely those of Spychiger et al. (1998; Oser \& Spychiger, 2005) and Heinze (2006). Both studies employed the same questionnaire as our research, but outlined distinct albeit comparable components: teacher behaviour (emotional and cognitive components), personal, emotional response to errors (error anxiety) and personal cognitive response to errors (learning orientation). All in all each study presents similar findings for the categories. Error anxiety rates consistently low, teacher behaviour is perceived as acceptable and while the levels in the learning oriented component are comparable, some improvement would be beneficial.

Table 4: Survey studies of Classroom Error Climate

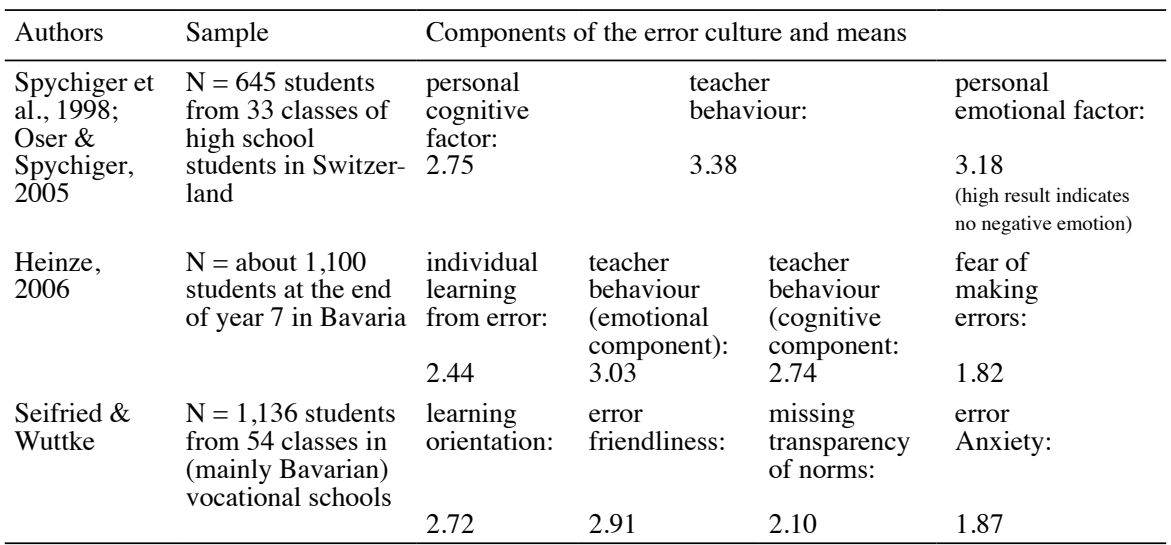

Note: 4 -point scale: $1=$ not true at all, $2=$ rather not true, $3=$ partly true, $4=$ completely true 


\subsection{Pilot study 2: Analysis of error situations and teachers' feedback}

\section{Method and Sample}

The data basis for this study consists of a pool of videoed lessons ( 10 hours of accounting lessons by two different teachers), which were filmed in vocational schools in Northern Bavaria. ${ }^{4}$ These teachers were primarily selected for their comparable (professional) biography. That is, male, about 40 years old, vocational training followed by vocational teacher education and, moreover, both have been working as teachers for about ten years. In order to be able to record the data in a narrow time frame (December 2006), both teachers were asked to hold five class hours (see table 5).

Table 5: Sample of the students participating in the video recording $(\mathrm{n}=38)$

\begin{tabular}{lll}
\hline & Class 1 $(\mathrm{n}=17)$ & Class 2 (n=21) \\
\hline Gender & $10 \mathrm{f}, 7 \mathrm{~m}$ & $18 \mathrm{f}, 3 \mathrm{~m}$ \\
Age (average, range) in years & $16,1(15$ to 17$)$ & $13,9(13$ to 16$)$ \\
Grade & 9 & 8 \\
School type & four-year & four-year \\
& commercial college & commercial college \\
Topic of lessons & accounting & accounting \\
\hline
\end{tabular}

\section{Identification of Error Situations}

Before analysing how teachers handle students' errors it was first necessary to identify error situations. We argue that an error situation is either defined when (1) teachers explicitly reject students' statements, or, (2) when they give another learner the floor without commenting on the first student's answer. The passing on of a question to another student contains the implicit message that the first answer was wrong (compare «ground rules» of communication in classrooms, Edwards \& Mercer 1987). An error sequence is comprised of a class discussion thematically matching and attributed to an error, but can include further errors in the course of discussion. The situation is completed when either the error is cleared up or the topic of the class discussion changes. This step of analysis is followed by a classification of the error situations.

\section{Classification of Error Situations}

In our view two conditions have to be fulfilled in order for error situations (mainly in class discussion) to hold learning potential:

4 The reported observation is embedded in a more extensive study about teachers' views on teaching, their actions during lessons and learning results of students (Seifried, 2009). 
(1) A study of Spychiger et al. (1998) shows that, from the learners' point of view, learning from errors is possible if teachers act in a supportive manner. A central condition for this is the recognition of the error(s) learners have made. This is possible if teachers actively use class discussions to «investigate» where the student's logical error lies. Therefore, it is a matter of determining whether teachers (or other persons in the classroom) make an attempt to «locate» the root of the error. Here, the obvious thing would be to analyse whether teachers try to get to the bottom of errors during the class discussion or simply ignore them.

(2) If a teacher has recognised an error then it is up to him or her to deal with it in an «appropriate» manner as learners can only understand errors and recognize courses of solution following qualified feedback. Therefore, a second dimension concerns the quality of teachers' feedback. Regarding the extent of elaboration during feedback, at least two forms are conceivable. Firstly, the teacher could reject the students' answer as wrong, without explaining this more thoroughly. Or, secondly, he could clearly state where the error lay and what a «correct» solution could look like, in the course of a detailed discussion (Wuttke, 2005; Mindnich, Wuttke \& Seifried, 2008; Wuttke, Seifried \& Mindnich, 2008). We therefore differentiate in low elaboration and high elaboration of feedback. Low elaboration means that the teacher rejects the answer by just stating that it is wrong (e.g. «no», «wrong», «this is not correct» etc.). High elaboration means that teachers give an extensive feedback that helps students to do better in future. Explanations are given as to why a solution is wrong and how it could be improved (Crespo, 2002).

Accordingly, we can see the first dimension as a necessary step in a process that is completed by the second dimension. Consequently, both conditions need to be fulfilled in order to assign learning potential to error situations in class discussions. We developed a coding system to analyse every error situation in reference to these two conditions. Table 6 shows the resulting typology of error situations which result from the above-mentioned statements.

Table 6: Typology of error situations in the class discussion

\begin{tabular}{|c|c|c|}
\hline \multirow{2}{*}{$\begin{array}{l}\text { Quality of } \\
\text { error search }\end{array}$} & \multicolumn{2}{|c|}{ Quality of feedback } \\
\hline & high & low \\
\hline $\begin{array}{l}\text { «Getting to } \\
\text { the bottom» }\end{array}$ & $\begin{array}{l}\text { type } 1 \\
\text { «getting to the bottom», } \\
\text { high elaboration }\end{array}$ & $\begin{array}{l}\text { type } 2 \\
\text { «getting to the bottom», } \\
\text { low elaboration }\end{array}$ \\
\hline $\begin{array}{l}\text { No «getting to } \\
\text { the bottom» }\end{array}$ & $\begin{array}{l}\text { type } 3 \\
\text { No «getting to the bottom», } \\
\text { high elaboration }\end{array}$ & $\begin{array}{l}\text { type } 4 \\
\text { No «getting to the bottom», } \\
\text { low elaboration }\end{array}$ \\
\hline
\end{tabular}


Obviously situation type 1 can be seen as a situation with learning potential. Here the teacher is willing to reveal an error («go into it») and can give elaborate feedback to help the learners recognise and correct their error. However, one would surely not assign any learning potential to situation type 4. Neither, is the error identified, («gotten to the bottom of») nor does the teacher provide high-quality feedback. In such situations learners cannot revise their possibly wrong concepts with regard to content and they do not know how to do better in future. In a type 3 situation the teacher does not explicitly get to the bottom of the error but provides high-quality feedback to an incorrect comment. Here the student recognizes indeed, that something in his/her answer was not as expected, but is not told where the problem actually lies. The learner's error provides a starting point for the teacher to once again explain a fact in detail. To completely reject the learning potential of this situation would be rash because it is possible that experienced teachers know exactly where the learners' (logical) flaws lie and therefore actively refrain from investigating the incorrect conclusion. Finally, situation type 2 should, at the most, hold a small amount of learning potential. In the case of a wrong statement the teacher «goes into it» but he/she does not give the learner elaborate feedback. Two explanations for this are possible: either the teacher recognizes the student's error, but from his view it is not worthwhile to address the issue in detail, or the teacher does not recognize the students' mistake, in spite of «going into it», and is not prepared to tackle the facts any further.

\section{Empirical Findings}

Altogether 76 error sequences were identified and assigned to one of the four types of error situations (see table 7 and Mindnich, Wuttke \& Seifried, 2008).

Table 7: Survey of the frequencies of the observed error situation types

\begin{tabular}{lccc}
\hline & $\begin{array}{c}\text { Teacher } \\
1\end{array}$ & $\begin{array}{c}\text { Teacher } \\
2\end{array}$ & Total \\
\hline $\begin{array}{l}\text { Error situation type 1 («getting to the bottom», high elaboration) } \\
\begin{array}{l}\text { Error situation type 2 («getting to the bottom», } \\
\text { no or low elaboration) }\end{array}\end{array}$ & - & 7 & 7 \\
$\begin{array}{l}\text { Error situation type } 3 \text { (no «getting to the bottom», } \\
\text { high elaboration) }\end{array}$ & - & 4 & 20 \\
$\begin{array}{l}\text { Error situation type } 4 \text { (no «getting to the bottom», } \\
\text { low elaboration) } \\
\text { Total }\end{array}$ & 15 & 30 & 45 \\
\hline
\end{tabular}

The results already show that the condition described as necessary for recognising the reasons for an error - the «getting to the bottom» - is rarely fulfilled in the analysed error sequences. Thereby, not even the first decisive step, that should be the 
basis for learning from errors, is present during class discussions. Moreover, the feedback reported here can hardly be described as elaborate. Therefore, error situation type 1 (high learning potential) is only rarely observed. Should such sequences actually turn out to be effective for learning not enough class time is given to them. High-quality feedback without error analysis (type 3) also occurs rarely. It is, however, different with error sequences of the second type. We frequently observed that teachers get to the bottom of the error, but then only give the learner very small clues, if any, about a better solution. Type 4 error sequences, on the other hand, occur frequently. Through an unfavourable response to errors teachers provide the learner with virtually no clues as to the error they made or how it could be remedied. Of course we are aware that the sample (two teachers, 5 lessons each) is rather small. We therefore consider these results as a preliminary indication that some teachers might not be qualified or willing to deal with errors in a way that fosters further learning. Therefore, our current study uses a much larger sample and a more systematic analysis of error response to investigate how teachers diagnose students' errors and react to them (see below).

\section{Summary and Outlook}

Learners from commercial schools report a positive error culture. The more positive aspects such as error friendliness and learning orientation rated highly, whereas fear of errors or missing norm transparency was hardly mentioned. Thus, the first condition for constructive dealing with error situations, as mentioned above, was fulfilled (pilot study 1).

Classroom observation, however, presented a different picture; especially regarding «adequate» dealing with error situations (pilot study 2). Here, it was shown that teachers do not always deal with learner errors constructively and do not systematically vary their error strategies according to the error situation. In many error situations insufficient encouragement was given to students to search for the solution themselves, and the teachers consistently failed to «get to the bottom» of the error. Of course, in view of the small sample size, our findings are not representative of the situation and should be considered carefully. But all in all it is to be assumed that teachers do not always handle error situations as constructively as they should.

Regarding the findings of the video study, the question that arises is: when will teachers acquire the know-how, strategies and views described by us as professional error competence. With this in mind, our current project focuses on how teachers develop competence in the areas of error diagnosis and dealing with learner errors. Because little is known about when teachers acquire error knowledge and ways of dealing with errors, we are using a longitudinal design, to test teachers at several stages of their development. Firstly, while studying (Bachelor, Master), then during their practical training, at the beginning of their working life and finally after two years of teaching. To begin with, we interviewed experts (teachers and students) about typical errors and error situations to identify typical domain specific errors. 
The findings of this interview-study formed the basis for the production of video vignettes. These vignettes present short error situations in the classroom and are being used as prompts to test if teachers are able to identify errors and how they respond. In addition, we are using a paper-pencil test to learn more about teachers' abilities to diagnose errors, and an adaption of the Error Orientation Questionnaire (Rybowiak et al., 1999) to analyse teachers' beliefs about learning from errors. This work is still in progress, but in the long run we expect to gain valuable information to improve teaching and teacher education.

\section{Appendix 1: Classroom-Error-Culture-Questionnaire}

(Spychiger et al., 1998; Spychiger, Kuster, \& Oser, 2006)

\section{Error friendliness (10 items)}

- The teacher is patient, if a student does not understand something in class.

- If the teacher makes a mistake he/she tries to hide it.

- When I make a mistake during class, the teacher addresses it in a way that really helps me.

- When the teacher makes a mistake, he/she acknowledges it.

- When I make mistakes in a written exercise, the teacher discusses it with me to help me.

- In class we feel that we shouldn't make mistakes because the teacher doesn't like it.

- Our teacher thinks that people who make mistakes are lazy.

- When I make a mistake in class, the teacher handles it in a way that I learn something new.

- The teacher is patient and does not tell me off, when I do not succeed with something.

- With our teacher making mistakes is never bad.

\section{Missing transparency of norms (8 Items)}

- I feel unsure because I make a lot of mistakes in class.

- When I make a mistake, I often do not understand why.

- I often do not know why, during lessons, I am growled at by the teacher.

- In my opinion, lots of misunderstandings occur during our lessons.

- Sometimes in class I am criticised for my behaviour, although I didn't know that it was wrong.

- I often do not understand what the teacher means.

- I often make mistakes in class because I do not understand the teacher's questions properly.

- Sometimes I have the feeling that my teacher does not understand me properly. 


\section{Learning orientation (8 Items)}

- Sometimes it helps if I remember a past mistake so I don't do it again.

- I always correct my tests by myself even when the teacher doesn't bring it up.

- When I get home, I always go over the mistakes I made in class.

- I enjoy trying to find different solutions to exercises.

- If I make a mistake I think about it a lot afterwards.

- It makes me happy when I learn something new by making a mistake.

- If I don't do something properly in class I see it as a chance to learn.

- Mistakes in class help me to do better next time.

\section{Error anxiety (5 Items)}

- I am scared of the teacher when I get back a test with lots of mistakes.

- I get scared when I make a mistake in class.

- I feel ashamed when I make mistakes in class.

- When I make mistakes in class I blame myself for not having learnt enough or for not paying attention.

- Before class I get scared that I will make mistakes during the lesson.

\section{References}

Baumert, J. \& Kunter, M. (2006). Stichwort: Professionelle Kompetenz von Lehrkräften. Zeitschrift für Erziehungswissenschaft, 9(4), 469-520

Bromme, R. (2005). Thinking and knowing about knowledge: A plea for and critical remarks on psychological research programs on epistemological beliefs. In M. H. G. Hofmann, J. Lenhard, \& F. Seeger (Eds.) Activity and sign - Grounding mathematics education. New York: Springer, 191-201

Cochran-Smith, M. (2001). Constructing outcomes in teacher education: Policy, practice and pitfalls. Educational Policy Analysis Archives, 9(11), http://epaa.asu.edu/epaa/vol9.html/

Crespo, S. (2002). Praising and correcting: prospective teachers investigate their teacherly talk. Teaching and Teacher Education, 18(6), 739-758

Desimone, L. M. (2009). Improving impact studies of teachers' professional development: Toward better conceptualizations and measures. Educational Researcher, 38(3), 181-199

Edwards, A. D. \& Mercer, N. (1987). Common knowledge: The development of understanding in the classroom. London and New York: Methuen

Ellström, P.-E. (2006). The meaning and role of reflection in informal learning at work. In D. J. Boud, P. Cressey, \& P. Docherty (Eds.). Productive reflection at work. London: Routledge, 43-53

Eraut, M. (1994). Developing professional knowledge and competence. London: Routledge Falmer

Fischer, M. A., Mazor, K. M., Baril, J., Alper, E., DeMarco, D., \& Pugnaire, M. (2006). Learning from mistakes. Factors that influence how students and residents learn from medical errors. Journal of General Internal Medicine, 21(5), 419-423

Galluzzo, G. R. \& Craig, J. R. (1990). Evaluation of preservice teacher education programs. In W. R. Houston, M. Huberman, \& J. Sikula (Eds.). Handbook of Research on Teacher Education. New York: MacMillan, 599-616

Gartmeier, M., Bauer, J., Gruber, H., \& Heid, H. (2008). Negative knowledge: Understanding professional learning and expertise. Vocations and Learning, 1(2), 87-103

Glendon, A. I., Clarke, S. G., \& McKenna, E. F. (2006). Human safety and risk management. Boca Raton, FL: Taylor and Francis 
Große, C. S. \& Renkl, A. (2007). Finding and fixing errors in worked examples: Can this foster learning outcomes? Learning and Instruction, 17(6), 612-634

Gschwendtner, T., Knöll, B., \& Nickolaus, R. (2007). Förderung und Entwicklung der Fehleranalysefähigkeit in der Grundstufe der elektrotechnischen Ausbildung. Berufs- und Wirtschaftspädagogik online (bwp@), Ausgabe 13 (Selbstorganisiertes Lernen in der beruflichen Bildung). http://www. bwpat.de/ausgabe13/gschwendtner_etal_bwpat13.pdf

Harteis, C., Bauer, J., \& Gruber, H. (2008). The culture of learning from mistakes: how employees handle mistakes in everyday work. International Journal of Educational Research, 47(4), 223-231

Heinze, A. (2006). Umgang mit Fehlern im Mathematikunterricht - Empirische Ergebnisse zur Schülerwahrnehmung. Beiträge zur Mathematikdidaktik, 251-255

Klein, T., Neumann, J., Reuter, M., Hennig, J., \& von Cramon, D.Y. (2007). Genetically determined differences in learning from errors. Science, 318 (5856), 1642-1645

Kunter, M., Klusmann, U., Dubberke, T., Baumert, J., Blum, W., Brunner, M., et al. (2007): Linking aspects of teacher competence to their instruction. Results from the COACTIV Project. In M. Prenzel, (Ed.): Studies on the educational quality of schools. The final report on the DFG Priority Programme. Münster: Waxmann, 32-52

Mindnich, A., Wuttke, E., \& Seifried, J. (2008). Aus Fehlern wird man klug? Eine Pilotstudie zur Typisierung von Fehlern und Fehlersituationen. In E.-M. Lankes (Hrsg.) Pädagogische Professionalität als Gegenstand empirischer Forschung. Münster u. a.: Waxmann, 153-163

Minnameier, G. (2008). Zur empirischen Analyse des Umgangs mit Fehlern im wirtschaftskundlichen Unterricht. In D. Münk, P. Gonon, K. Breuer, \& T. Deißinger (Hrsg.) Modernisierung der Berufsbildung. Neue Forschungserträge und Perspektiven der Berufs- und Wirtschaftspädagogik. Schriftenreihe der Sektion BWP der DGfE. Opladen: Barbara Budrich, 120-130

Minsky, M. (1994). Negative expertise. International Journal of Expert Systems, 7(1), 13-19

Müller, A. (2003). Fehlertypen und Fehlerquellen beim Physiklernen. Was weiß die Denkpsychologie? Praxis der Naturwissenschaften - Physik in der Schule, 52(1), 11-18

Nordstrom, C. R.; Wendland, D., \& Williams, K. B. (1998). «To err is human»: an examination of the effectiveness of error management training. Journal of Business and Psychology, 12(3), 269-282

Oser, F. \& Spychiger, M. (2005). Lernen ist schmerzhaft. Zur Theorie des negativen Wissens und zur Praxis der Fehlerkultur. Weinheim \& Basel: Beltz

Oser, F., Hascher, T., \& Spychiger, M. (1999). Lernen aus Fehlern. Zur Psychologie des negativen Wissens. In W. Althof (Hrsg.) Fehlerwelten. Vom Fehlermachen und Lernen aus Fehlern. Opladen: Leske + Budrich, 11-41

Parviainen, J. \& Eriksson, M. (2006). Negative knowledge, expertise and organisations. International Journal of Management Concepts and Philosophy, 2(2), 140-153

Rybowiak, V., Garst, H., Frese, M., \& Batinic, B. (1999). Error Orientation Questionnaire (EOQ): Reliability, validity and different language equivalence. Journal of Organizational Behavior, 20(4), 527-547

Schoenfeld, A. H. (1985). Mathematical problem solving. Orlando: Academic Press

Schoenfeld, A. H. (2002). How can we examine the connections between teachers' world views and their educational practices? Issues in Education, 8(2), 217-227

Schütz, A. (1932). Der sinnhafte Aufbau der sozialen Welt. Eine Einleitung in die verstehende Soziologie. Wien: Julius Springer. English translation: The Phenomenology of the Social World (1967). Evanston, IL: Northwestern University Press

Seifried, J. (2009). Unterricht aus der Sicht von Handelslehrern. Frankfurt/Main: Lang

Spychiger, M., Mahler, F., Hascher, T., \& Oser, F. (1998). Fehlerkultur aus der Sicht von Schülerinnen und Schülern. Der Fragebogen S-UFS: Entwicklung und erste Ergebnisse. Schriftenreihe zum Projekt «Lernen Menschen aus Fehlern? Zur Entwicklung einer Fehlerkultur in der Schule», Nr. 4. Pädagogisches Institut der Universität Freiburg/Schweiz

Spychiger, M., Kuster, R., \& Oser, F. (2006). Dimensionen von Fehlerkultur in der Schule und deren Messung. Der Schülerfragebogen zur Fehlerkultur im Unterricht für Mittel- und Oberstufe. Schweizerische Zeitschrift für Bildungswissenschaften, 28, 87-110

Tjosvold, D., Yu, Z., \& Hui, C. (2004). Team Learning from Mistakes. The Contribution of Cooperative Goals and Problem-Solving. Journal of Management Studies, 41(7), 1223-1245 
Van Dyk, C.; Frese, M.; Baer, M., \& Sonnentag, S. (2005). Organizational error management culture and its impact on performance: a two-study replication. Journal of Applied Psychology, 90(6), 1228-1240

Van Woerkom, M. (2003). Critical reflection at work. Bridging individual and organisational learning. Enschede: PrintPartners

Weimer, H. (1925). Psychologie der Fehler. Leipzig: Klinkhardt

Wills, A. J., Lavric, A., Croft, G. S., \& Hodgson, T. L. (2007). Predictive learning, prediction errors, and attention. Evidence from event-related potentials and eye tracking. Journal of Cognitive Neuroscience, 19(5), 843-854

Wuttke, E. (2005). Unterrichtskommunikation und Wissenserwerb. Zum Einfluss von Kommunikation auf den Prozess der Wissensgenerierung. Frankfurt/Main: Lang

Wuttke, E., Seifried, J., \& Mindnich, A. (2008). Umgang mit Fehlern und Ungewissheit. In M. GläserZikuda \& J. Seifried (Hrsg.) Lehrerexpertise. Analyse und Bedeutung unterrichtlichen Handelns. Münster: Waxmann, 91-111

Yerushalmi, E. \& Polingher, C. (2006). Guiding students to learn from mistakes. Physics Education, $41(6), 532-538$ 